\title{
Bioquímica em Poesia: uma experiência de ensino de Bioquímica Médica utilizando metodologia colaborativa na graduação do curso de Medicina
}

\section{Biochemistry in poetry: A teaching experience using collaborative learning methodology to learning Medical Biochemistry to medical graduated students}

Prado, S.R.T. ${ }^{*}$

${ }^{1}$ Curso de Medicina, Pontifícia Universidade Católica do Paraná, Curitiba, Paraná, Brasil

*e-mail: srtprado@gmail.com

\begin{abstract}
Resumo
A aprendizagem da Bioquímica requer alto grau de pensamento abstrato, incluindo a imaginação para entender os processos metabólicos dos seres vivos no seu nível molecular e é vista pelos estudantes com muita dificuldade. Esta atividade trata de um método de aprendizagem colaborativa, proposta de modo a conectar conteúdos científicos de Bioquímica com a Literatura. Estudantes da disciplina de Bioquímica do curso de Medicina, $1^{\circ}$ semestre/2016, organizados em 29 grupos com 3-4 estudantes tiveram de elaborar um poema a partir de conteúdo específico de Bioquímica. A apresentação do poema se deu oralmente, por postagem virtual, assim como impresso no formato de pôster e de livro. A avaliação feita pelos estudantes apontaram que elaborar textos próprios de poesia com analogia do conteúdo teórico foi muito difícil e difícil, respectivamente, para a maioria dos grupos; $73 \%$ deles disseram que a atividade foi eficaz na aprendizagem de uma nova habilidade e $79 \%$ afirmaram ter sido positivo para aprenderem um tópico específico de Bioquímica. Os resultados obtidos sugerem que a atividade colaborativa promoveu maior aprendizagem do tema trabalhado pelo estudante, assim como maior conhecimento sobre busca e abordagem do tema. Outras habilidades desejadas no perfil do egresso como a capacidade de trabalhar em grupo e expor seu trabalho de forma escrita e oral para o público foram exercitadas, assim como o desenvolvimento do pensamento crítico e construção de argumento.
\end{abstract}

Palavras-chave: ensino de Bioquímica; aprendizagem colaborativa; poema bioquímico.

\begin{abstract}
Generally, the learning of Biochemistry is too hard for college student. Biochemistry required the abstract thinking to understanding the molecular level the metabolism of living. The Biochemical learning experience carried out connecting Biochemistry and Literature to provide a collaborative learning method. The students of the School of Medicine, first semester 2016 was organized in 29 groups each with 3-4 students and they had to write a poem with a specific theme related to Biochemistry that had to write the poem and presents it to class orally, to expose a poem's banner and all groups together had to organize a printed book. Instead other points the evaluation sheet from students pointed out to elaborate own texts and used academic vocabulary about Biochemistry theme were too hard and hard, respectively; $73 \%$ of them said the activity help them to learning a new thing and $79 \%$ agree that the activity help them to learning the specific Biochemistry topic. This demonstrates the need of activities that exercise writing on biochemical topics collaborating with the scientific growth of the college students. This activity promoted major learning about specific Biochemistry theme and the development to others desired skills in the profile of that the course proposes, like to collaborative work and to present your work in public. Instead that, to use a different learning methodology helps students develop the abstract thinking necessary for Biochemistry learning.
\end{abstract}

Keywords: biochemistry learning; collaborative methodology; biochemical poem. 
National award: Biochemistry in poetry: A teaching experience using collaborative learning methodology to learning Medical Biochemistry to medical graduated students

\section{Ficha da atividade/ material}

\begin{tabular}{|c|c|}
\hline Título & $\begin{array}{l}\text { Bioquímica em Poesia: uma experiência do ensino de Bioquímica Médica } \\
\text { utilizando metodologia colaborativa na graduação do curso de Medicina }\end{array}$ \\
\hline Categoria: & Prática de Ensino \\
\hline Tipo & Atividade colaborativa em grupo \\
\hline Público-alvo: & Estudantes de graduação do curso de Medicina \\
\hline $\begin{array}{l}\text { Conteúdos } \\
\text { abordados }\end{array}$ & $\begin{array}{l}\text { Lipogênese; Lipólise; Metabolismo das lipoproteínas e Aterosclerose; } \\
\text { Fisiopatologia do Diabetes mellitus; Complicações do Diabetes mellitus e sua } \\
\text { Fisiopatologia; Controle da Ingesta Alimentar e Obesidade. }\end{array}$ \\
\hline $\begin{array}{l}\text { Objetivos } \\
\text { educacionais }\end{array}$ & $\begin{array}{l}\text { (a)Aprofundar um tema de Bioquímica a partir de ferramenta didática usando } \\
\text { metodologia ativa; (b)desenvolver a competência de trabalhar em pequenos } \\
\text { grupos; (c)motivar a prática pedagógica; (d)estimular a prática do processo } \\
\text { reflexivo; (e)exercitar o pensamento crítico; (f)possibilitar uma nova experiência } \\
\text { de aprendizagem da Bioquímica usando a literatura; (g)praticar a busca e } \\
\text { avaliação de fonte de informação apropriada; (h)praticar autonomia de estudo e } \\
\text { responsabilidade; (i)desenvolver a habilidade de estudo a partir de um novo } \\
\text { método; (j)desenvolver a capacidade de escrita; (k)experimentar um modo } \\
\text { diferente de estudar um tema específico da sua área; (l)praticar a elaboração e } \\
\text { apresentação de painel para apresentação de trabalho; (m)praticar a habilidade } \\
\text { de comunicação oral e escrita; (n)desenvolver suas habilidades cognitivas e } \\
\text { criatividade; (o)estimular a reflexão para auto-avaliação. }\end{array}$ \\
\hline Duração & Aproximadamente 90 dias. \\
\hline $\begin{array}{l}\text { Materiais } \\
\text { utilizados }\end{array}$ & $\begin{array}{l}\text { Os alunos tiveram acesso à bibliografia recomendada da disciplina, assim como } \\
\text { artigos científicos relacionados com todos os temas propostos para a atividade. } \\
\text { Foi disponibilizado sistema multimídia para as apresentações orais. }\end{array}$ \\
\hline Criação & $13 / 02 / 2016$ \\
\hline Aplicação & $15 / 03 / 2016-10 / 06 / 2016$ \\
\hline
\end{tabular}


National award: Biochemistry in poetry: A teaching experience using collaborative learning methodology to learning Medical Biochemistry to medical graduated students

\section{Introdução}

Os conteúdos da Bioquímica explicam os diversos fenômenos moleculares nos seres vivos ${ }^{[1]}$ e são considerados de difícil aprendizagem para os estudantes dos anos iniciais dos cursos da área da saúde, os quais têm a Bioquímica como uma área fundamental de conhecimento. Essa dificuldade resulta de vários aspectos dentre eles a necessidade do conhecimento prévio da Química e Biologia ofertados durante o Ensino Médio, o qual segmenta completamente os conhecimentos dessas áreas, tendo se mostrado muito aquém da necessidade para sua compreensão ${ }^{[2]}$.

Portanto, deve-se lançar mão da aprendizagem significativa, que prioriza o desenvolvimento cognitivo, a capacidade de abstração e pensamento criativo, na qual a estrutura cognitiva está constantemente se reestruturando, num processo dinâmico no qual o conhecimento vai sendo construído ${ }^{[3]}$, favorecendo a aprendizagem da Bioquímica. É conhecido que estudantes aprendem mais efetivamente através da aprendizagem ativa, pois estimula o aprofundamento da aprendizagem e o engajamento ${ }^{[4]}$ e oportuniza 0 desenvolvimento de múltiplas habilidades simultaneamente, como o pensamento crítico, análise da literatura, habilidades oral e escrita associadas à análise da comunicação ${ }^{[5 ; 6 ; 7]}$.

$\mathrm{Na}$ aprendizagem significativa novos conhecimentos adquirem significado para o sujeito a partir da re-significação dos conhecimentos prévios adquirindo maior estabilidade cognitiva $^{[8]}$. A aprendizagem colaborativa permite a colaboração entre os estudantes para a compreensão do tema e tem potencial de promover estímulo ao pensamento crítico; ao desenvolvimento de capacidades de interação, negociação de informações e resolução de problemas; ao desenvolvimento da capacidade de autorregulação do processo de ensino-aprendizagem ${ }^{[9]}$.

A prática de ensino aqui apresentada está baseada na aprendizagem colaborativa, propiciando a inter-relação pessoal, com troca de opinião, capacidade de escutar e argumentar. Além disso, prioriza a co-construção do conhecimento, a comunicação e possibilita que os estudantes usem analogias para desenvolverem um texto poético a partir de um conteúdo teórico e o uso de analogias tem sido importante para esclarecer e facilitar a aprendizagem de conceitos científicos ${ }^{[10 ; 11 ; 12]}$. Além das analogias, imagens e metáforas também são recursos que podem favorecer a comunicação de ideias científicas $^{[13 ; 14]}$, sendo o uso desses recursos reconhecido como importantes aliadas na vida acadêmica dos estudantes e têm sido objeto de investigações no campo da educação em ciências ${ }^{[15 ; 16 ; 17]}$.

De acordo com Gomes \& Messeder ${ }^{[18]}$, a maior parte dos materiais desenvolvidos 
National award: Biochemistry in poetry: A teaching experience using collaborative learning methodology to learning Medical Biochemistry to medical graduated students

no estudo de ensino de Bioquímica refere-se ao uso de ambiente virtual de aprendizagem, aplicativos, DVD, fórum e realidade virtual e software. Contudo, a abordagem do ensino da Bioquímica deve ser o mais diversificado possível para dar oportunidade e vontade de se apropriarem dos conhecimentos científicos, de modo que metodologias diversificadas contribuem para o ensino-aprendizagem e devem ser inseridas na prática didática, ampliando o caminho para o desenvolvimento do pensamento crítico-reflexivo ${ }^{[19 ; 20]}$. Diversas estratégias de aprendizagem ativa têm sido propostas em disciplinas científicas para abordar esses desafios pedagógicos ${ }^{[21 ; 22]}$ e evidências cognitivas contemporâneas indicam que experiências e contextualização promove a construção do conhecimento e retenção da informação ${ }^{[23 ; 24]}$.

Essas reflexões acima, somados à observação feita por Hartfield ${ }^{[5]}$ de que o ambiente de aprendizagem ativa oportuniza o desenvolvimento de múltiplas habilidades simultaneamente, incluindo a auto-avaliação do conteúdo, o questionamento e a argumentação como habilidades desejáveis no ensino das ciências ${ }^{[6}$, foram motivos que levaram à construção da presente prática de ensino, a qual foi pensada e estruturada de forma a utilizar um processo dinâmico que não tivesse sido extensamente aplicada e que permitisse a prática e desenvolvimento de diversas habilidades e competências pelos estudantes do curso de Medicina.

Sendo assim, vários foram os objetivos de aprendizagem desta proposta pedagógica: (a)Aprofundar um tema de Bioquímica a partir de ferramenta didática usando metodologia ativa; (b)desenvolver a competência de trabalhar em pequenos grupos; (c)motivar a prática pedagógica; (d)estimular a prática do processo reflexivo; (e)exercitar o pensamento crítico; (f)possibilitar uma nova experiência de aprendizagem da Bioquímica usando a literatura; (g)praticar a busca e avaliação de fonte de informação apropriada; (h)praticar autonomia de estudo e responsabilidade; (i)desenvolver a habilidade de estudo a partir de um novo método; (j)desenvolver a capacidade de escrita; (k)experimentar um modo diferente de estudar um tema específico da sua área; (I)praticar a elaboração e apresentação de painel para apresentação de trabalho; $(\mathrm{m})$ praticar a habilidade de comunicação oral e escrita; (n)desenvolver suas habilidades cognitivas e criatividade; (o)estimular a reflexão para auto-avaliação.

\section{Desenvolvimento}

Esta atividade foi desenvolvida em grupos de 3-4 alunos. A escolha de elaborar essa atividade em grupo se deu pela percepção da necessidade de um trabalho cada vez 
National award: Biochemistry in poetry: A teaching experience using collaborative learning methodology to learning Medical Biochemistry to medical graduated students

mais multidisciplinar em praticamente todos os campos de atuação profissional, inclusive e particularmente, na área da saúde, onde há grande necessidade de trabalhos em grupo, um processo ativo de troca e produção de conhecimento, e não somente difusão de informações, um conhecimento apropriado e condizente com cada realidade.

A atividade foi proposta no 10 mês de aula, a partir da formação dos grupos e sorteio do tema de Bioquímica para cada grupo, dentre os pré-determinados: Lipogênese; Lipólise; Metabolismo das lipoproteínas e Aterosclerose; Fisiopatologia do Diabetes mellitus; Complicações do Diabetes mellitus e sua Fisiopatologia; Controle da Ingesta Alimentar e Obesidade, sendo que mais de um grupo abordava o mesmo tema. A descrição, normas e orientações, conteúdos e critérios de avaliação para desenvolvimento da atividade foram disponibilizados para os alunos previamente à atividade e estão apresentados no apêndice $A$.

\section{Procedimentos de uso do material ou aplicação da atividade}

Após elaborada a atividade, esta foi apresentada aos grupos que iniciaram a prática com a reflexão sobre como fariam para elaborar o texto poético abordando o tema sorteado. Com o apoio de 4 monitores das disciplinas de Bioquímica, orientados pelo professor, foi possibilitando a produção do material. Além dos monitores, o professor também esclareceu dúvidas dos grupos, de modo que o desenvolvimento da atividade foi acompanhado pelo professor durante todo o processo. Isto se fez necessário para favorecer a construção do conhecimento até porque alguns grupos abordaram temas que ainda não tinham sido ministrados na disciplina até a data final da realização da atividade.

A entrega da atividade iniciou em torno de 70 dias após o começo da elaboração da atividade, com a entrega do texto escrito pelo Sistema de intranet da disciplina, ficando disponível para todos os grupos. Depois, cada grupo apresentou um pôster com o texto produzido permanecendo até o final do semestre letivo nas paredes do bloco de Ciências Biológicas e da Saúde (apêndices D e E).

$\mathrm{Na}$ terceira semana ocorreu a apresentação oral da poesia elaborada por grupo, o qual teve a liberdade de definir a forma de apresentação. A premissa foi que declamassem o poema escrito por eles para a sua turma podendo ao final incluir comentários e esclarecimentos. A maioria dos grupos usou apresentação em slides animados com algum nível de dramatização, o que deixou a apresentação interessante e atraente. No final de cada apresentação houve um tempo para arguição sobre o tema pelos outros estudantes e pelo professor e na sequência, os grupos fizeram uma auto- 
National award: Biochemistry in poetry: A teaching experience using collaborative learning methodology to learning Medical Biochemistry to medical graduated students

avaliação (Apêndice B) pré-elaborada e finalmente, houve um diálogo (debate) sobre os pontos fortes e fracos, fáceis e difíceis da atividade proposta com sugestões de melhoria no procedimento e desenvolvimento da atividade, assim como propostas para atividades futuras.

No apêndice $G$ estão apresentados alguns exemplos dos textos produzidos pelos grupos. No total, foram elaborados 29 poemas, os quais foram compilados no formato de livro, além dos pôsteres apresentados pelos grupos.

\section{Procedimentos de avaliação}

Neste trabalho, optou-se por escolher, como temas para o desenvolvimento da atividade, tópicos inclusos no Conteúdo Programático da disciplina de Bioquímica Médica II, os quais estão listados no apêndice A. Como o número de estudantes era grande, mais de um grupo abordou o mesmo tema, permitindo que a turma tivesse mais de uma visão para um mesmo tema, podendo assim, ler diferentes textos poéticos que abordasse o mesmo assunto.

O trabalho teve como foco central a produção do texto no formato de poesia de tema de Bioquímica e a apresentação do trabalho ocorreu de diversas maneiras, permitindo a avaliação de mais de uma habilidade de apresentar um trabalho. O valor atribuído à atividade na disciplina correspondeu ao peso 2 na nota do $2^{\circ}$ bimestre. Os critérios de avaliação utilizados foram estabelecidos contemplando todas as apresentações, oral e escrita, realizadas pelos grupos e estão descritas a seguir:

1. Uso correto de conceitos bioquímicos, assim como vocabulário de cunho acadêmico e científico (nível de conhecimento e conteúdo abordado no texto elaborado) $=1,0$;

2. Elaboração e redação do texto com uso gramatical correto $=0,3$;

3. Presença e participação da apresentação do trabalho $=0,3$;

4. Criatividade e qualidade do material impresso e da apresentação $=0,4$.

Os procedimentos adotados para este trabalho e que foram apresentados aos estudantes no início da atividade, assim como alguns dos materiais produzidos estão apresentados no apêndice $A$. 
National award: Biochemistry in poetry: A teaching experience using collaborative learning methodology to learning Medical Biochemistry to medical graduated students

\section{Potencial educacional}

A National Research Council (1996), in Hartfield ${ }^{[5]}$, ressalta de que a obtenção de pensamento crítico e desenvolvimento de habilidades é o objetivo central da educação de graduandos nas áreas de Ciências e que a aprendizagem de Bioquímica deve se dar através de atividades de aprendizagem que enfatizam a proximidade com os complexos conceitos e sistemas biológicos, devendo este preceito guiar o design de atividades de ensino-aprendizagem.

As competências e habilidades adquiridas durante a aprendizagem ativa é crítica e discriminativa para uma aprendizagem autêntica e algumas delas darão uma vantagem competitiva aos estudantes no mercado de trabalho do mundo real ${ }^{[25]}$. Metodologias diversificadas podem contribuir para o ensino-aprendizagem da Bioquímica e devem ser inseridas na prática didática, ampliando o caminho para o desenvolvimento do pensamento crítico-reflexivo ${ }^{[19 ; 20]}$. A utilização de tais metodologias pode favorecer a autonomia do educando, despertando a curiosidade, estimulando tomadas de decisões individuais e coletivas, advindos das atividades essenciais da prática social e em contextos do estudante ${ }^{[26 ; 27 ; 28]}$.

A atividade colaborativa, desenhada para ser aplicada aos estudantes de Medicina, se caracteriza pela interação entre conhecimentos prévios e conhecimentos novos permitindo o uso de analogia e metáfora para o desenvolvimento do texto poético proposto e estas correspondem a modelos de ensino que podem atuar como mediadoras no processo de ensino-aprendizagem ${ }^{[29]}$, subsidiando o processo de aprendizagem significativa, levando o sujeito a reestruturar informações prévias ou formar novos esquemas cognitivos ${ }^{[30]}$.

A prática de ensino aqui apresentada está baseada na aprendizagem colaborativa e além do desenvolvimento de habilidades necessárias para o trabalho colaborativo, esta prática também prioriza a co-construção do conhecimento, a comunicação e o pensamento reflexivo. Muitos alunos relataram ter tido muito tempo de reflexão antes de iniciar a elaboração do texto e também precisaram estudar mais profundamente o tema antes que pudesse convertê-lo num texto poético plausível e inteligível. Estes depoimentos permitem relacionarmos o processo de construção desta atividade como sendo uma experiência reflexiva, sem a qual não é possível uma experiência significativa ${ }^{[31]}$.

Outro ponto apontado pelos alunos foi sobre o desafio de escrever um poema, algo 
National award: Biochemistry in poetry: A teaching experience using collaborative learning methodology to learning Medical Biochemistry to medical graduated students

que não faz parte da sua formação profissional específica. Para tanto, foram obrigados a pensar de forma diferente do que praticavam, fazendo com que tivessem de refletir muito para reorganizar o pensamento a fim de dar forma de texto poético a respeito do tema sobre o qual tinham de escrever. Isto também pode ser correlacionado com a idéia de Romanowsky \& Dorigon ${ }^{[32]}$, os quais usam o termo professional artistry para designar as competências que o indivíduo revela em situações únicas e de conflito e pode ser expressado através da observação e da reflexão sobre a ação. Nesta visão podemos concluir que esta atividade tem o potencial de desenvolver habilidades como o pensamento reflexivo, colaborativo, corroborando com maior capacidade de abstração necessária a aprendizagem de várias ciências, dentre elas a Bioquímica.

O uso da analogia, pelos estudantes, entre um conteúdo de interesse seu e o tema da Bioquímica, a fim de criar o texto poético, pode ser observado na escolha de um pano de fundo para criação de vários poemas, a exemplo da poesia: Para viver com diabetes, o qual fez uso de analogia (letra de um poema conhecido=para viver um grande amor; uma rotina familiar=bom almoço de mãe) e metáfora (... diacilglicerol vai ainda ser mais chatinho) ou da poesia: Diabetes, a complicação da minha vida, na qual também podemos encontrar analogia (ah, que saudade eu tenho da minha saúde sadia...) e metáfora (esse sorbitol é bem danado), concretizado no texto poético criado, e desta forma, contextualizando um conhecimento já adquirido anteriormente pelo qual os estudantes tinham alguma simpatia.

Pensando na premissa de que o ensino de Bioquímica deve ser o mais diversificado possível, essa prática de ensino foi desenhada para o estudante estar continuamente num processo de aprendizagem enquanto produzia o material final, o livro "Bioquímica em Poesia", e assim, possibilitar a prática de diferentes habilidades e competências com uma única atividade proposta durante todo o semestre letivo. Desta forma, os muitos objetivos educacionais propostos neste projeto, assim como o potencial de aprendizagem das diversas habilidades e competências torna essa prática de ensino abrangente e inovadora.

\section{Diferencial com as atividades/materiais preexistentes}

Este trabalho foi desenvolvido no 20 período do curso de Medicina e fazia parte de um Projeto de Aprendizagem das disciplinas de Bioquímica Médica I e II, denominado de "Bioquímica e Arte". Neste projeto, a cada semestre era aplicada uma proposta de atividade relacionada às artes e/ou literatura (teatro, curta metragem, conto, passatempo, 
National award: Biochemistry in poetry: A teaching experience using collaborative learning methodology to learning Medical Biochemistry to medical graduated students

dentre outras), de modo que os estudantes já sabiam que fariam alguma atividade abordando conteúdos de Bioquímica de modo pouco convencional, ou seja, de uma maneira diferente. Como esta atividade era aplicada no $1^{\circ}$ período do curso de Medicina, havia continuidade na prática deste processo de aprendizagem reflexiva em grupo de um semestre para o outro, com crescimento da complexidade dos conteúdos estudados.

Da revisão bibliográfica realizada, nenhuma atividade com esta abordagem de aprendizagem da Bioquímica foi encontrada, a não ser aprendizagem ativa baseada em grupos. Porém, apesar desta atividade tratar-se de uma atividade colaborativa, tem mais implicações na aprendizagem, uma vez que o estudante precisou, além de conteúdo teórico e colaboração com o grupo, do pensamento abstrato e criatividade para a inserção do conhecimento teórico num quadro fictício/real para a elaboração do poema.

Além disso, a aplicação desta atividade englobou diversas fases de elaboração e formas de apresentação do trabalho elaborado, permitindo que várias e diferentes combinações de habilidades e competências fossem praticadas e/ou desenvolvidas pelos estudantes, como a elaboração de texto poético, com necessidade de reflexão e inserção do conteúdo num contexto real, exigindo compreensão do tema para criar uma história a partir do conteúdo teórico e dar-lhe um formato poético; a elaboração e apresentação de pôster para a comunidade acadêmica; a apresentação oral do poema elaborado para a turma, incluindo arguição do conteúdo; a realização de uma avaliação reflexiva sobre a atividade e uma auto-avaliação após a apresentação de todos os grupos. Ainda, tiveram que elaborar de um material único, contendo todos os poemas escritos por todos os grupos, de modo que a turma toda precisou se auto-organizar para obter um material final com formato de livro.

A produção textual desta atividade pode ser usada para estimular a leitura de um tópico de Bioquímica, já que além de lúdico, as poesias são curtas e ritmadas e por isso, pode ser mais atrativa aos nossos estudantes que tem demonstrado poucos hábitos de leitura. Além de serem textos mais motivadores para os estudantes, poderiam ser avaliados quanto ao seu potencial de promover o aprendizado de conteúdos específicos de Bioquímica a partir do texto poético.

Como mencionado, a maioria das atividades aplicadas e descritas na literatura focam na produção de um material final enquanto essa prática de ensino possibilitou ao estudante praticar diferentes habilidades e competências com uma única atividade proposta durante o semestre. Desta forma, os muitos objetivos educacionais propostos neste projeto, assim como o potencial de aprendizagem das diversas habilidades e 
National award: Biochemistry in poetry: A teaching experience using collaborative learning methodology to learning Medical Biochemistry to medical graduated students

competências torna essa prática abrangente e inovadora.

\section{Resultados da avaliação}

A apresentação do poema produzido pelos grupos ocorreu oralmente, por postagem virtual, assim como no formato impresso de pôster e de livro. A avaliação oral feita pelos estudantes apontaram que a atividade demandou mais tempo que os trabalhos normalmente solicitados nas disciplinas em geral, porém ficaram felizes em ver o resultado final. Na auto-avaliação (apêndices B e C) relataram que elaborar textos próprios de poesia com analogia do conteúdo teórico foi muito difícil e difícil, respectivamente, para a maioria dos grupos; $73 \%$ deles disseram que a atividade foi eficaz na aprendizagem de uma nova habilidade e $79 \%$ afirmaram ter sido positivo para aprenderem um tópico específico de Bioquímica. Na auto-avaliação também foram inseridas questões dissertativas sobre a atividade e algumas respostas.

Os resultados obtidos sugerem que a atividade colaborativa promoveu maior aprendizagem do tema trabalhado pelo estudante, assim como maior conhecimento sobre busca e abordagem do tema, observada, principalmente durante a arguição dos grupos. Outras habilidades desejadas no perfil do egresso, como a capacidade de trabalhar em grupo e expor seu trabalho de forma escrita e oral para o público, foram exercitadas assim como o desenvolvimento do pensamento crítico e construção de argumento.

A percepção do nível de argumentação e questões abordadas durante as apresentações revelou crescimento, por parte dos estudantes, na complexidade de raciocínio e argumentação dos conteúdos teóricos, o que pode ser associado com a execução da atividade.

\section{Considerações finais}

A aplicação desta metodologia pretendeu possibilitar a vivência de um processo de aprendizagem reflexiva e colaborativa, corroborando com a aprendizagem de Bioquímica e o desenvolvimento de competências e habilidades importantes: a reflexão, senso crítico, organização e capacidade de trabalhar em grupo. A auto-avaliação indicou melhor conhecimento e entendimento do tema e a necessidade da reflexão constante.

Esta atividade demandou muito tempo para organização, acompanhamento e, principalmente para o processo de avaliação final, que incluiu a correção dos textos e dos banners, assim como da apresentação oral da poesia por todos os grupos, separados em 6 horários diferentes. Portanto, é necessário estar ciente desta demanda, pois é 
National award: Biochemistry in poetry: A teaching experience using collaborative learning methodology to learning Medical Biochemistry to medical graduated students

fundamental que o professor tenha o tempo disponível para cumprir todas as etapas com qualidade, principalmente para não desmotivar a turma.

Analisando os vários aspectos da aplicação da atividade e seus resultados, podemos concluir que esta atividade tem o potencial de desenvolver competências e habilidades desejadas para a aprendizagem de várias ciências, dentre elas a Bioquímica. A percepção do nível de argumentação e questões abordadas pelos estudantes revelou um crescimento na complexidade de raciocínio e associação dos conteúdos teóricos, o que pode ser associado com a execução da atividade.

É uma atividade muito interessante, que pode apresentar ainda maior nível de aprendizagem se houver mais professores envolvidos, o que permitiria mais momentos de discussão dos temas de Bioquímica durante o desenvolvimento do trabalho de todos os grupos, o que levaria ao enriquecimento do senso crítico e argumentativo. E além disso poderia-se trabalhar de forma inter e multidisciplinar com o envolvimento de outros docentes de outras disciplinas enriquecendo o processo ensino-aprendizagem.

Futuramente, os textos poéticos produzidos devem ser avaliados para verificar seu potencial de aprendizagem por terceiros a fim de validar o uso das poesias elaboradas como um material de aprendizagem da Bioquímica. É sem dúvida, um material muito rico.

\section{Referências}

[1] Gomes, K.V. G.; Rangel, M. Relevância da disciplina bioquímica em diferentes cursos de graduação da UESB, na cidade Jequié. Rev. Saúde. Com. v.2, n.1, 2006, p. 161-168. Disponível em:

<http://www.uesb.br/revista/rsc/v2/v2n2a8.pdf> Acesso em 02/01/2019.

[2] Loguércio et al., 2007 Loguercio, R., Souza, D. e Pino, J. C. D. Mapeando a educação em bioquímica no Brasil. Revista Ciências e Cognição. 2007; 10: 147-155.

[3] Moreira, M.A., Caballero, M.C. e Rodríguez, M.L. (orgs.) (1997). Actas del Encuentro Internacional sobre el Aprendizaje Significativo. Burgos, España. pp. 19-44. <https://www.if.ufrgs.br/ moreira/apsigsubport.pdf> Acesso em 02/01/2019. (Revista Brasileira de Física, Vol. 9, NP 1, 1979. A Teoria de Aprendizagem de David Ausubel como Sistema de Referência para a Organizaçilo de Conteúdo de Física* M. A. MOREIRA.

[4] Marton, F., \& Säljö, R. (1976) On qualitative differences in learning. II: Outcome as a function of the learner"s conception of task. British Journal of Educational Psychology, 46, 115 - 127; in: Hartfield, P.J. 2010.

[5] Hartfield, P.J. (2010) Reinforcing constructivist teaching in advanced level biochemistry through the introduction of case-based learning activities. QUT FaST Science Educators' Symposium: Selected papers (October 2010) 2010 Vol. 3 No.3.

[6] Gardner, J. \& Belland, B.R. (2012). A conceptual framework for organizing active learning experiences in biology instruction. Journal of Science and Educational Technology, 21, 465-475. In: Kulak \& Newton 2015.

[7] Borges e Alencar. Metodologias ativas na promoção da formação crítica do estudante: o uso das metodologias ativas como recurso didático na formação crítica do estudante do ensino superior Cairu em Revista. Jul/Ago 2014, Ano 03, nº4, p. 1 19-143, ISSN 22377719. 
National award: Biochemistry in poetry: A teaching experience using collaborative learning methodology to learning Medical Biochemistry to medical graduated students

[8] Ausubel, D. P. A aprendizagem significativa: a teoria de David Ausubel. São Paulo: Moraes, 1982.

[9] Torres, P.L; Irala, E.A. Aprendizagem colaborativa: Teoria e Prática. Coleção Agrinho. $<$ http://www.agrinho.com.br/site/wp-content/uploads/2014/09/2_03_Aprendizagem-colaborativa.pdf > Acesso em 02/01/2019.

[10] Carmo, E. A. Analogias como instrumentos úteis para o ensino do conteúdo químico no nível médio. Belém: UFPA, 2006.

[11] Figueroa, A. M. S.; Nagem, R. L.; Carvalho, E. M. Metodologia de ensino com analogias: um estudo sobre a classificação dos animais. Encontro Nacional de pesquisa em educação em ciências, 4.,2003. Bauru. Anais eletrônicos... Bauru: ENPEC, 2003 Disponível em:<http://www.rieoei.org/deloslectores/842Senac.PDF>. Acesso em: 02/01/2019.

[12] Nunes, R. R.; Ferraz, D. F.; Justina, L. A. D. Estudos relativos a analogias no ensino de ciências. In: Justina, L. A. D.; Ferraz, D. F. (Org.). Coleção Biologia em Foco 1: Conhecimentos Biológicos e Ensino de Ciências e Biologia. $1^{\text {a }}$ ed. Cascavel: Edunioeste, v. 1, p. 23- 36, 2009.

[13] Martins, I.; Gouvea,G.; Piccinini,C. Aprendendo com imagens. Revista da Sociedade Brasileira para o Progresso da Ciência, ano 57, n.4, p.38-40, 2005.

[14] Perrelli, M. A. S. Metáforas como objeto em ensino de ciências. Florianópolis: Universidade Federal de Santa Catarina, 1994.

[15] Duarte, M. C. Analogias na educação em ciências: contributos e desafios. Investigações em Ensino de Ciências, Porto Alegre, v. 10, p. 7-29, 2005.

[16] HOFFMANN, M. B., SCHEID, N. M. J. Analogias como ferramenta didática no ensino de biologia. Ensaio Pesquisa em Educação em Ciências, Belo Horizonte, v. 9, n.1, p. 1-17, 2007. Disponível em: < http:// www.scielo.br/pdf/epec/v9n1/1983-2117-epec-9-01-00021.pdf >. Acesso em: 02/01/2019.

[17] Pádua, I. C. A. Analogias, metáforas e a construção do conhecimento: por um processo ensinoprendizagem mais significativo. Pontíficia Universidade Católica (MG), 2010.

[18] Gomes, L.M.J.B. \& Messeder, J.C. A presença das TIC no ensino de Bioquímica: uma investigação para uma análise crítica da realidade. Atas do IX Encontro Nacional de Pesquisa em Educação em Ciências - IX ENPEC Águas de Lindóia, SP - 10 a 14 de novembro de 2013.

[19] Gordillo, M. M. El enfoque CTS y la educación sobre las TIC. Buenos Aires, IBERTIC, 2012. Disponível em: $<$ https://www.youtube.com/watch?v=IT1iD4eDdXs> Acesso em 02/01/2019.

[20] Bruner, J. 1961 p.60 The act of discovery. Harvard Educational Review, 31, 21-32. In: Hartfield, 2010.

[21] Robitaille, N.. The revitalization of undergraduate education in Canada. A report on the AUCC workshop in undergraduate education. Halifax, Nova Scotia. Association of Universities and College of Canada, 2011. $<$ https://www.univcan.ca/wp-content/uploads/2015/11/revitalization-of-undergraduate-education-in-canadamarch-2011.pdf> Acesso em 02/01/2019.

[22] V. Kulak \& G. Newton. An Investigation of the Pedagogical Impact of Using Case-based Learning in a Undergraduate Biochemistry Course. International Journal of Higher Education Vol. 4, No. 4; 2015.

[23] Ward, P. J.. First year medical students' approaches to study and their outcomes in a gross anatomy course. Clinical Anatomy, 24(1), 120-127; 2011. In V. Kulak \& G. Newton 2015.

[24] Eberlein, T., Kampmeier J., Minderhout, V., Moog, R.S., Platt, T., Varma-Nelson, P., \& White, H.B. (2008). Pedagogies of engagement in Science. Biochemistry and Molecular Biology Education, 36, 262-273.

[25] Handelsman, J., Ebert-May, D., Beichner, R., Burns, P., Chang, A., DeHaan, R., Gentile, J., Lauffer, S., Stewart, J., Tilghman, S.M., \& Wood, W.B. (2004). Scientific teaching. Science, 304, 521-522.

[26] Biggs, J. \& Tang, C.. Teaching for quality learning at university (3rd ed.). Berkshire, UK: Open University 
National award: Biochemistry in poetry: A teaching experience using collaborative learning methodology to learning Medical Biochemistry to medical graduated students

Press/McGraw-Hill Education; 2007. In Hartfield, 2010.

[27] Oliveira, PS. Estrutura e função das proteínas nos livros didáticos de biologia aprovados no PNLD 2012. Dissertação de Mestrado [Biologia Geral]. Instituto de Biofísica Carlos Chagas Filho, Universidade Federa do Rio de Janeiro.

[28] Dorigon, Thaisa C.; Romanowski, Joana P. Revista Intersaberes, Curitiba, ano 3, n. 5, p. 8 - 22, jan/jul 2008 Disponível em: <http://www.uninter.com/intersaberes/index.php/revista/article/view/123/96> Acesso em $02 / 01 / 2019$.

[29] Monteiro, I.; Justi, R. Analogias em livros didáticos de química brasileiros destinados ao ensino médio. Investigações em ensino de Ciências. v.5, n. 2, p.1-24, 2000. Disponível em:< https://www.if.ufrgs.br/cref/ojs/ index.php/ienci/article/view/650/441>. Acesso em: 02/01/2019.

[30] DUIT, R. On the role of analogies ad metaphors in learning science. Science Education, v.75, n.6, p- 649 $-672,1991$.

[31] Dewey, John. Experiência e educação. 3a ed. São Paulo: Nacional, 1979.

[32] Dorigon, Thaisa C.; Romanowski, Joana P; apud: SCHON, D. Educando o Profissional Reflexivo: um novo design para o ensino e aprendizagem. Trad. Roberto Cataldo Costa. Porto Alegre: Artes Médicas Sul, 2000.

\section{Agradecimentos}

Aos alunos da disciplina de Bioquímica Médica II do Curso de Medicina da PUCPR, 10 semestre de 2016, pela participação e dedicação no desenvolvimento deste trabalho, assim como nas apresentações orais, várias delas muito criativas. 
Apêndice A. A descrição, normas e orientações, critérios de avaliação para

desenvolvimento da atividade.

\author{
A PONTIFICIA UNIVERSIDADE CATÓLICA DO PARANÁ \\ ESCOLA DE MEDICINA - $2^{\circ}$ PERIODO - $1^{\circ}$ semestre 2016 \\ DISCIPLINA DE BIOQUIMICA MÉDICA II - Profa. Silvia R.T. Prado \\ ATIVIDADE COMPLEMENTAR - $\underline{V A L O R}=2,0$ na prova 2
}

TEMA: BIOQUIIMICA ELITERATURA

A atividade deverá ser feita em grupos de 3 alunos organizados dentro da sua turma de prática.

O trabalho a ser elaborado é uma atividade de elaboração de texto no formato de poema ou poesia musicada (ver ANEXO II), abordando um dos temas de Bioquímica listados no anexo ao final deste documento. Os temas e o tipo de atividade serão sorteados entre os grupos.

\title{
NORMAS DO TRABALHO:
}

I. Cada grupo deverá elaborar a sua atividade em até 3 páginas $\mathrm{A4}$, usando o word, letra calibri 12 , espaçamento 1,5 e salvar no formato docx. Os textos deverảo ser entregues no molde de 1 livro único de poesias, com o título: "Bioquímica em Poesia", na qual todas as atividades de todos os grupos deverảo estar inseridas com os nomes dos estudantes que elaboraram logo abaixo do título, justificado à direita da página. Na capa deverá constar o título da revista, período e turma, disciplina, professor, ano. Este material deve ser entregue impresso e postado no Eureka (pasta trabalhos) até a $2^{\wedge}$ FEIRA que preceder as apresentações (ver cronograma).

II. Além do livvro, todos deverăo entregar: 1. a composiçăo impressa antes do início da apresentaçăo (deve conter o número do grupo, participantes e tema); 2. a ficha de avaliação preenchida e assinada pelos membros do grupo (a ser postada no Eureka); 3. o arquivo com a produção da atividade deverá ser postado no Eureka, na mesma pasta trabalhos para que todos possam ter acesso aos materiais dos grupos que nåo puderam estar na apresentação oral dos outros grupos. O nome do arquivo deve conter o número do grupo e o tema.

IIL. Os trabalhos deverảo ser apresentados na forma de pôster afixados na parede do corredor das coordenações, no bloco verde, onde permanecerảo por uma semana. Um pôster maior, impresso (em papel tamanho AO) deverá ser elaborado mostrando a capa do livro, e informações sobre o trabalho (número de grupos, temas, quais tipos de atividades foram elaborados). Além disso, cada grupo deverá imprimir seu texto elaborado numa folha A2 e também afixar nas paredes ao lado do pôster da capa do livro. (Sugestão: organizar 1 grupo com alunos de diferentes grupos para ela borar o pōster com a capa)

OBS: será descontado 0,2 da nota obtida no trabalho para o grupo que não cumprir alguma das atividades listadas nas normas do trabalho.

A apresentaça será feita em dia, horário e local a ser confirmado em data mais próxima e cada grupo apresentará sua atividade, oralmente (pode ser na forma de jogral, teatro ou outra) para o restante da turma, com duração máxima de aproximadamente, 6 minutos. Todo grupo deverá estar presente e poderá ter argu ição sobre o tema a presentado. Na apresentaçăo, a poesia deverá estar musicada.

OBS.: Caso o trabalho (o livro impresso e postagem no Eureka) não seja entregue na data prevista, assim como o pôster e os trabalhos expostos, será descontado 0,4 da nota obtida no trabalho.

Objetivos:

Compreender um assunto relacionado à Bioquímica utilizando uma ferramenta didática com metodologia ativa; aprofundar mais o conhecimento de um tema novo ou já estudado; desenvolver a capacidade de estudo a partir de outro método; praticar a autonomia de estudo; desenvolver a capacidade de elaboraçāo de texto com conteúdo científico; elaborar um pôster no formato de apresentaçăo em eventos cientificos; desenvolver a capacidade apresentação oral e de responder à argüição de um assunto de estudo; praticar a capacidade de trabalhar em grupo. 
National award: Biochemistry in poetry: A teaching experience using collaborative learning methodology to learning Medical Biochemistry to medical graduated students

Critérios para avaliação:

1. uso correto de conceitos bioquimicos, assim como vocabulário de cunho acadêmico e científico (nível de conhecimento e conteúdo abordado no texto elaborado) $=1,0$;

2. elaboração e redação do texto com uso gramatical correto $=0,3$;

3. presença e participação da apresentação do trabalho $=0,3$;

4. criatividade e qualidade do material impresso e da apresentação $=0,4$

ANEXO I - TEMAS ESCOLHIDOS PARA O TRABALHO.

1. METABOLISMO DE LIPIDIOS (UIPOGÊNESE)

2. METABOLISMO DE LIPÍDIOS (LIPÓLISE)

3. LIPOPROTEINAS E ATEROSCLEROSE

4. DIABETES MEUITUS (FISIOPATOLOGIA)

5. DIABETES MEUITUS (FISIOPATOLOGIA DAS COMPLICAÇÕES)

6. CONTROLE DA INGESTA ALIMENTAR E OBESIDADE

\section{ANEXO II}

Diferenças entre poesia, poema e soneto

http://portugues.uol.com.br/literatura/diferencas-entre-poesia-poema-soneto.html

A poesia: Certa vez o escritor Oswald de Andrade disse a seguinte frase: "Aprendi com meu filho de 10 anos que poesia é o descobrimento das coisas que nunca vira antes". A poesia pode estar em tudo: em uma situação cotidiana, em uma paisagem, em uma fotografia, nas artes plásticas e em um poema. Isso significa que a poesia não é exclusividade da literatura, tampouco do poema. A poesia está associada a uma atitude criativa, e não a um gênero titerário. $\hat{E}$ uma definição mais ampla, que pode estar presente em diversas manifestações artisticas. Responder à pergunta "O que é poesia?" nem sempre é tarefa fácil, deixando sem palavras até mesmo o experiente poeta Manuel Bandeira:

"Eu, que desde os dez anos de idade faço versos; eu, que tantas vezes sentira a poesia passar em mim como uma corrente elétrica e afluir aos meus olhos sob a forma de misteriosas lágrimas de alegria: não soube no momento forjar jä não digo uma definição racional dessas que, segundo regra a lógica, devem convir a todo o definido e só ao definido, mas uma definição puramente empirica, artistica, literäria".

Manuel Bandeira

O poema: Elemento pertencente ao gênero lírico, o poema é um gênero textual que apresenta caracteristicas que permitem identificá-lo entre os demais gêneros: é um texto composto em versos e estrofes, em uma oposição aos textos compostos em prosa (textos escritos em parágrafos, ou seja, em línhas longas). Um bom poema geralmente está carregado de poesia, mas hả também poemas que recusam qualquer tirismo. São recursos muito empregados no poema a musicalidade, a repetição e a linguagem metafórica, essa última responsável por conferir ao texto maior subjetividade. 
National award: Biochemistry in poetry: A teaching experience using collaborative learning methodology to learning Medical Biochemistry to medical graduated students

\title{
Apêndice B. Ficha de auto-avaliação
}

\author{
DISCIPLINA DE BIOQUÍMICA MÉDICA \\ Profa. Dra. Sillvia R.T. Prado \\ FiCHA DE AVALIAÇĀo DA ATIVIDA DE BIOQUímiCA E ARTE: Poema e poesia - 2016-1
}

PERÍDO E TURMA: $\underset{\text { ASSUNTO: }}{\text { No grupo: — ESTUDANTES (nome) }}$ (assinatura)

-

Nós, estudantes acima assinad os, concordamos com o uso dos dados queaqui constam para fins academicos e também estamos de acordo com a ediçăo do trabalho produzido, para correçâo gramatical ou de erros de conteúdo, com o objetivo de divulgaçă o em melos de divulgaçấo em massa, académica e/ou cientifica, respeitando a autoria do trabalho.

Esta ficha de avaliaçâo é apenas a opiniảo dos alunos sobre o trabalho propos to e será usado como um direcionamento e coleta de dados para alteraçđes e melhoria na proposta de um novo trabalho futuro e não terá qualqquer efeitosobre a avaliaçio do grupo em relaçâo ao trabal ho apresentado. Agradeço a colaboraçâo dos qque responde rem honestamente.

Assinale o grau de facilidade ou dificuldade no desenvolvimento ou execução de cada item:

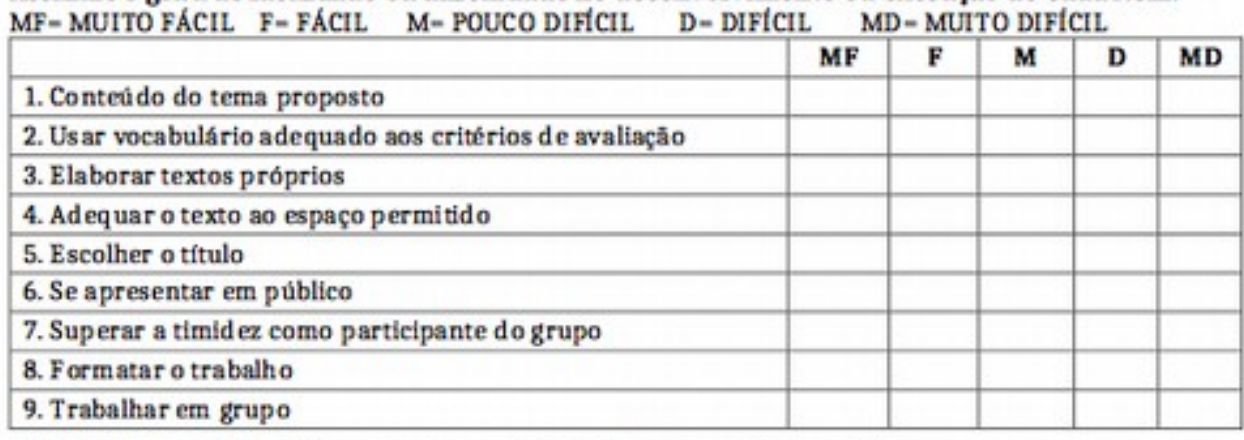

Atribuir uma nota (0 a 10) em relaçâo a este trabalho, para cada item abaixo:

1. Quanto ajudou a aprender algo novo:

2.Quanto ajudou a aprender o tema (conteúdo da disciplina) do trabalho:

3. Quanto ajudou a lidar corn as diferentes opinioes dentro do grupo:

4. Quanto ajudou a exercitarem o"fa lar em publico":

5. Quanto foi prazeroso elaborar a ativilade, apesar das dificuldades:

6. Quanto fol prazeroso ver o trabalho pronto:

Responder:

1. Alguem do grupo já havia elaborado algum tipo de poesh alguma vez? Quantos?

2. Este trabalho a uxiliou na aprendizagem de algo novo alem do conteudo da disciplina? 0 que?

3. Voces manteriam o mesmo grupo em outro trabalho posterior? Porque?

4. Aposver o trabalho dos outros grupos, honestamente, qual nota $(0$ a 10$)$ voces dariam para o trabal ho de voces? 5.0 qque voces mudariam e/ou melhorariam no trabalho se tivessem tempo para isso?

6. Abaixo, atribuir uma nota $(0$ a 10$)$ para cada membro dogrupo quuanto à participaçio no desenvolvimento desta atwidade.

7. Sugestóes e criticas. 


\section{Apêndice C. Ficha de auto-avaliação preenchida por um dos grupos}

\section{DISCIPLINA DE BIOQUIMICA MÉDICA}

Profa. Dra. Silvia R.T. Prado

FICHA DE AVALIAÇÃo DA ATIVIDADE BIOQUÍMICA E ARTE: Poesia e poema - 2016-1

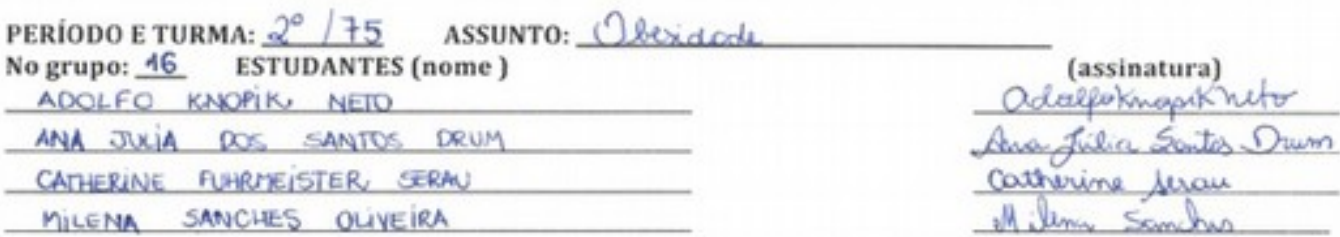

Nós, estudantes acima assinados, concordamos com o uso dos dados que aquí constam para fins acadêmicos e também estamos de acordo com a edição do trabalho produzido, para correçăo gramatical ou de erros de conteúdo, com o objetivo de divulgação em meios de divulgaçẫo em massa, acadêmica e/ou cientifica. respeitando a autoria do trabalho.

Esta ficha de avaliação é apenas a opinião dos alunos sobre o trabalho proposto e será usado como um direcionamento e coleta de dados para alteraçōes e melhoria na proposta de um novo trabalho futuro e nảo terá qualquer efeito sobre a avaliação do grupo em relaçăo ao trabalho apresentado. Agradeço a colaboraçâo dos que responderem honestamente.

Assinale o grau de facilidade ou dificuldade no desenvolvimento ou execução de cada item:

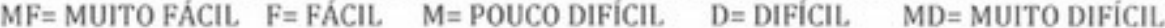

\begin{tabular}{|l|c|c|c|c|c|}
\hline 1. Conteúdo do tema proposto & MF & F & M & D & MD \\
\hline 2. Usar vocabulário adequado aos critérios de avaliação & & & X & & \\
\hline 3. Elaborar textos próprios & & & & $X$ & \\
\hline 4. Adequar o texto ao espaço permitido & & & $X$ & & \\
\hline 5. Escolher o título & & $X$ & & & \\
\hline 6. Se apresentar em público & & $X$ & & & \\
\hline 7. Superar a timidez como participante do grupo & & $X$ & & & \\
\hline 8. Formatar o trabalho & & & $\times$ & & \\
\hline 9. Trabalhar em grupo & & & \\
\hline
\end{tabular}

Atribuir uma nota $(0$ a 10$)$ em relação a este trabalho, para cada item abaixo:

1. Quanto ajudou a aprender algo novo: 10

2. Quanto ajudou a aprender o tema (conteúdo da disciplina) do trabalho: to

3. Quanto ajudou a lidar com as diferentes opiniōes dentro do grupo:

4. Quanto ajudou a exercitarem o "falar em público": $\quad 8$

5. Quanto foi prazeroso elaborar a atividade, apesar das dificuldades: $\quad 9$

6. Quanto foi prazeroso ver o trabalho pronto: 10

Responder:

1. Alguém do grupo já havia elaborado algum tipo de poesia ou poema alguma vez? Quantos? nöo, nentuem integante de guupe

2. Este trabalho auxiliou na aptendizagem de algo novo além do conteúdo da disciplina? 0 que?

Ním da aprendizagem, poi muito impertante pora nós vermas que va fixacäo do

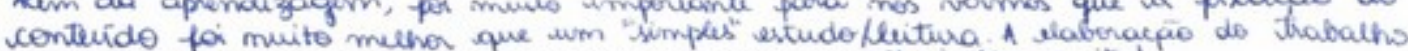
3. Vocês manteriam o mesmo grupo em outro trabalho posterior? Porque? rás ajudour 'muito !

Sim, poir todos integrantes participaram efitivamente da elaberacäo do trabalto i friam próatives.

4. Após ver o trabalho dos outros grupos, honestamente, qual nota $(0$ a 10$)$ vocês dariam para o trabalho de vocếs? 10

5.0 que vocès mudariam e/ou melhorariam no trabalho se tivessem tempo para isso?

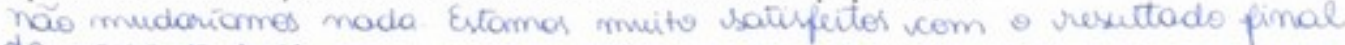

de messe trabalke

6. Abaixo, atribuir uma nota $(0$ a 10$)$ para cada membro do grupo quanto à participação no desenvolvimento desta atividade.

$$
\text { Adole } \rightarrow 10 \quad \text { Cothuline } \rightarrow 10
$$

Ana sulio $\rightarrow 10 \quad$ nilena $\rightarrow 10$

7 Sinectine e criticas

$$
\text { nilura } \rightarrow 10
$$

Apesar da dificuldade, gertamas muito de elaborar a poesea. Actorros que fai

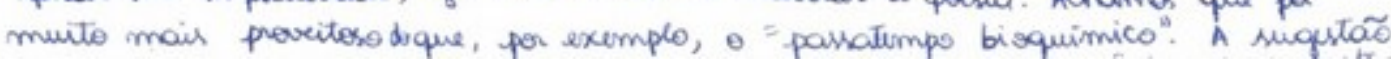


National award: Biochemistry in poetry: A teaching experience using collaborative learning methodology to learning Medical Biochemistry to medical graduated students

Apêndice D. Banner de apresentação dos trabalhos expostos da Disciplina de Bioquímica Médica II.

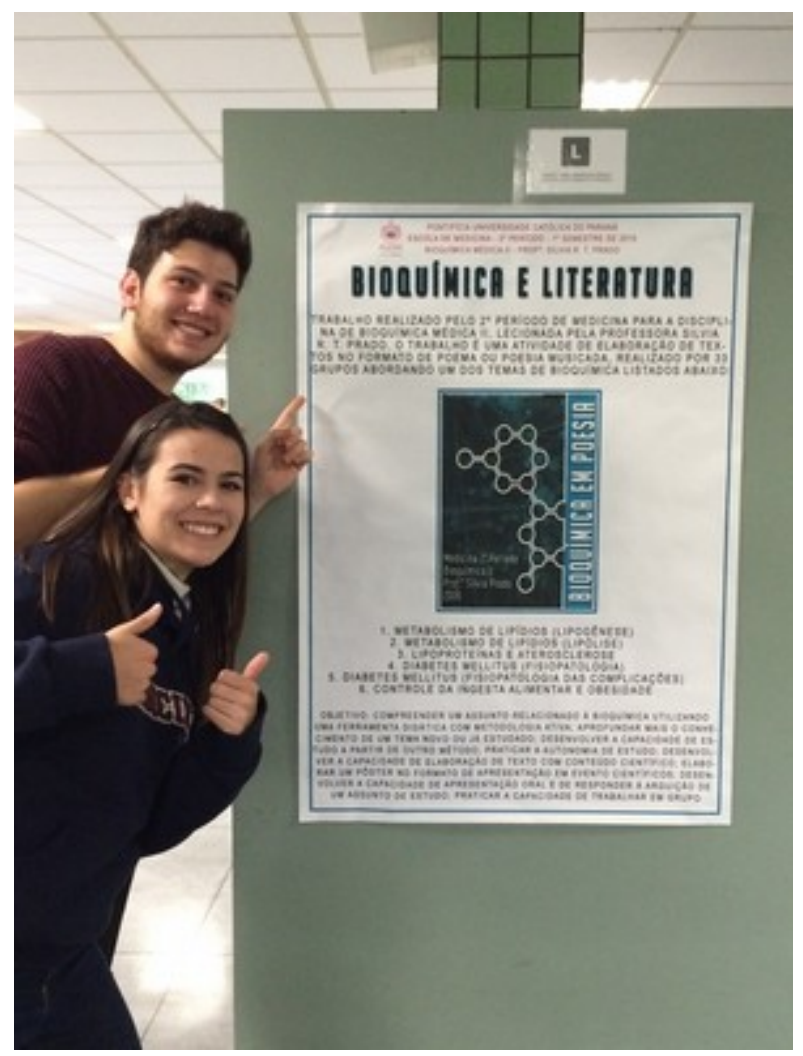

Apêndice E. Banners expostos de poesias elaboradas por 2 grupos participantes da atividade.

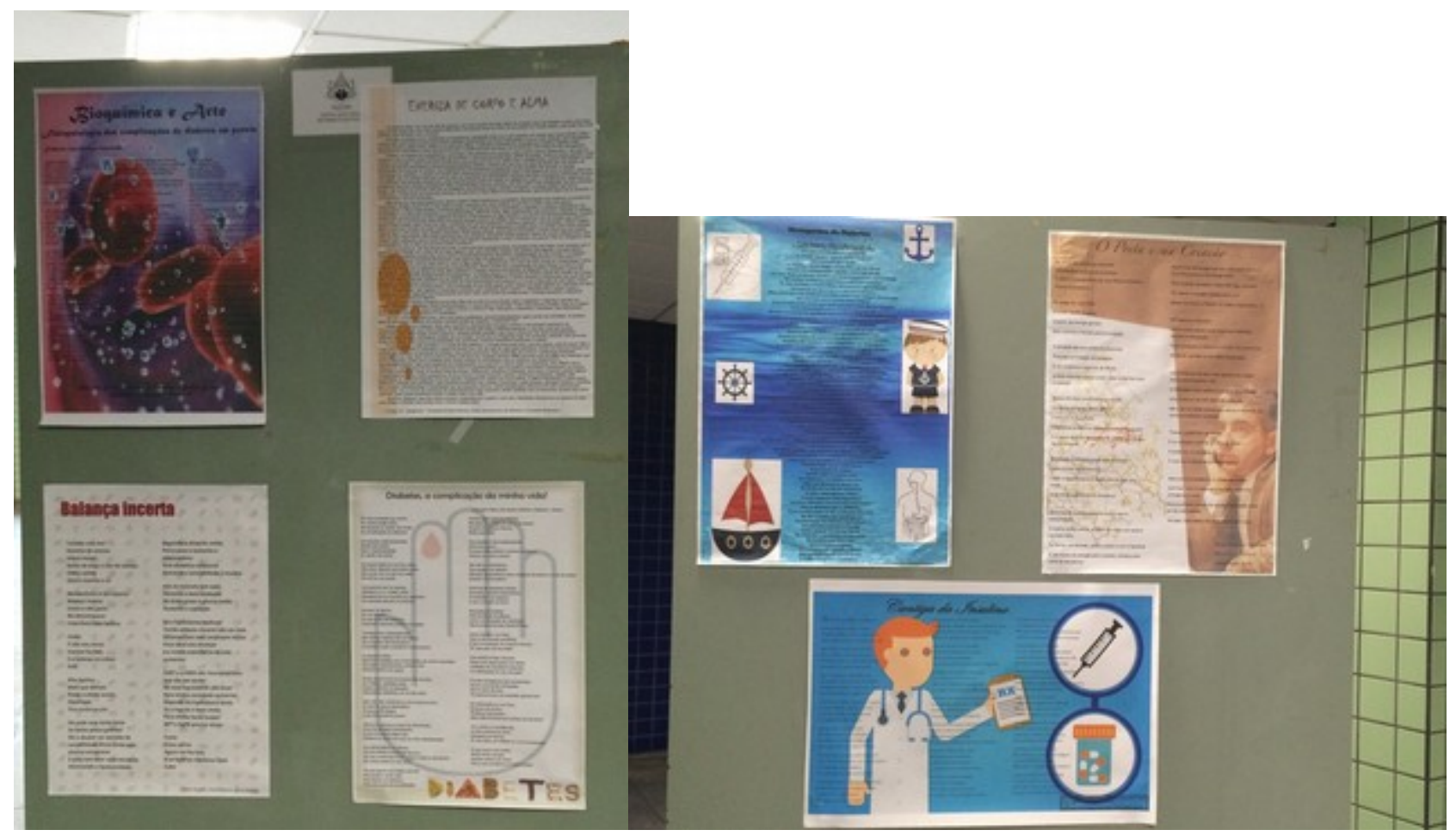


National award: Biochemistry in poetry: A teaching experience using collaborative learning methodology to learning Medical Biochemistry to medical graduated students

Apêndice F. Livro contendo as poesias elaboradas por todos os grupos.

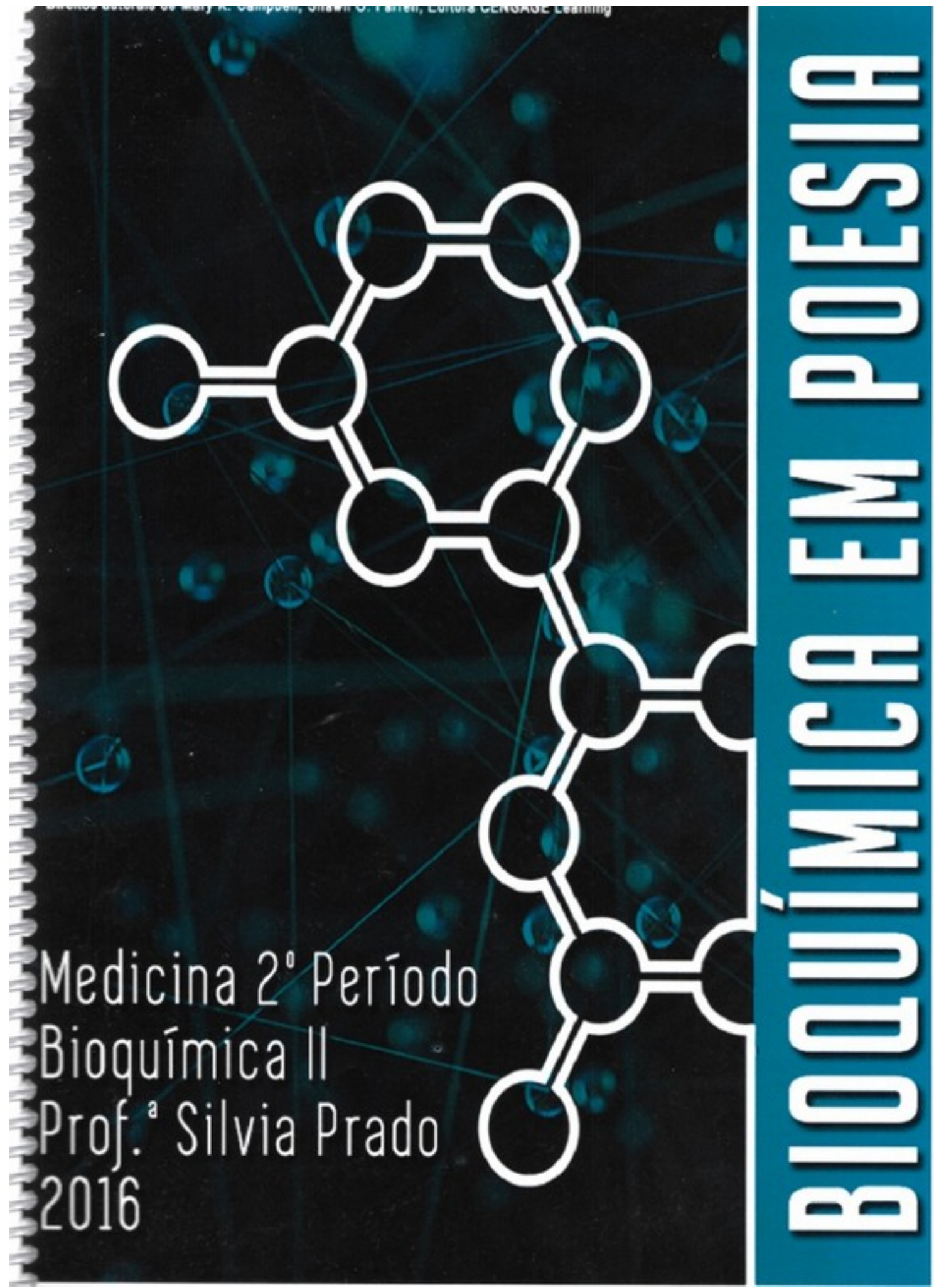


Apêndice G. Poemas produzidos por alguns grupos.

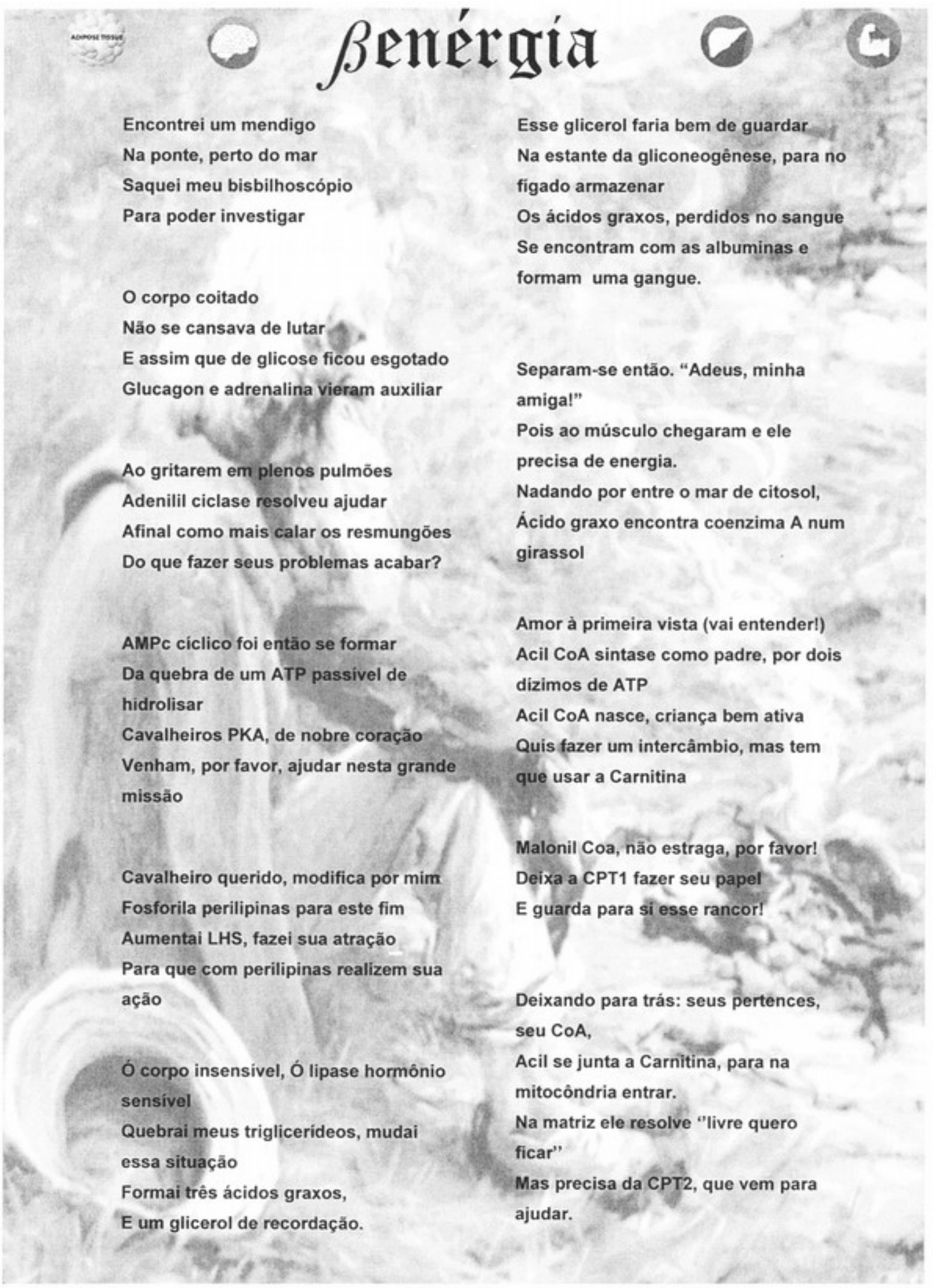

Poema elaborado a partir do tema Lipólise e beta-oxidação, parte 1. 
National award: Biochemistry in poetry: A teaching experience using collaborative learning methodology to learning Medical Biochemistry to medical graduated students

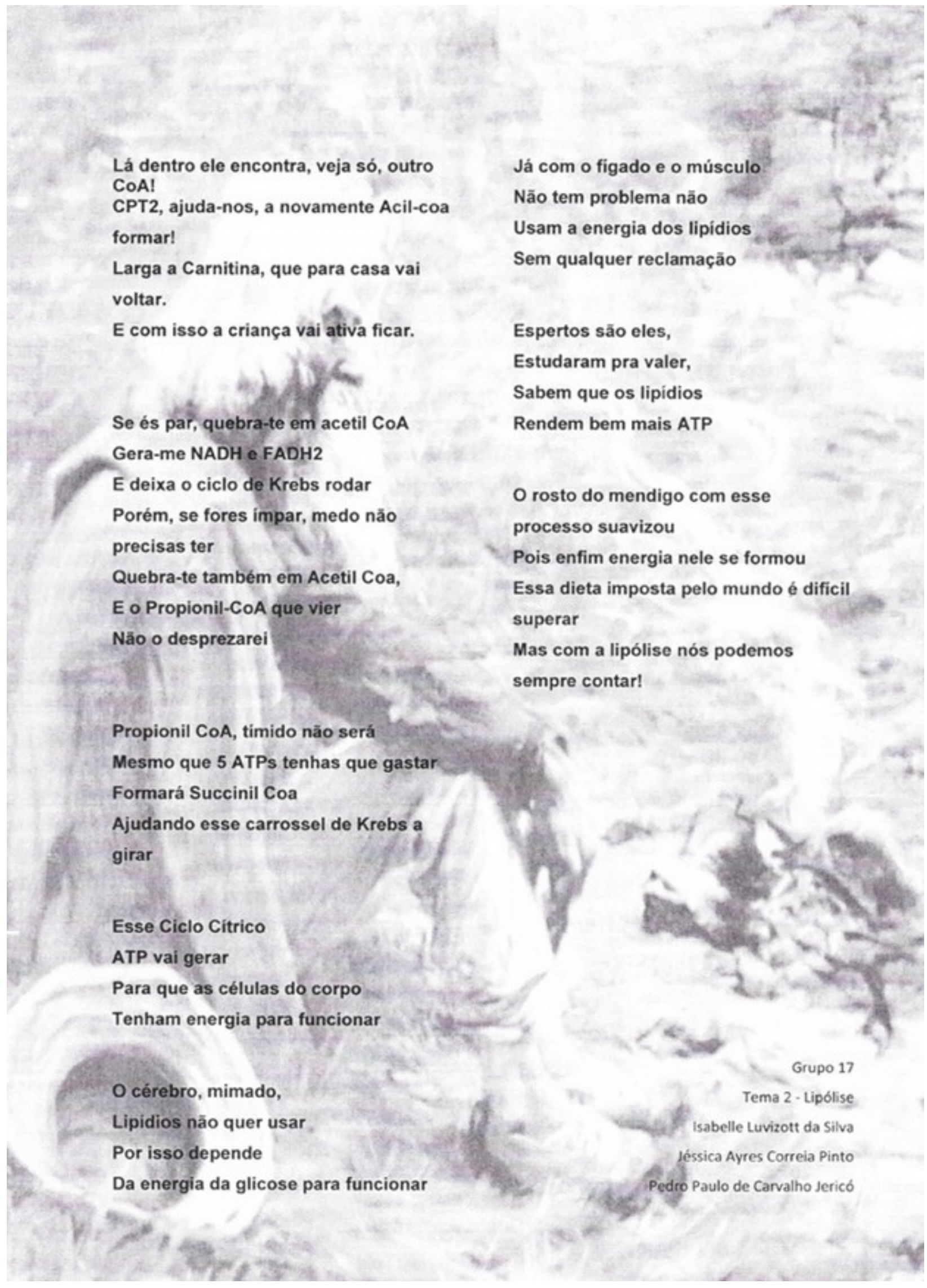

Poema elaborado a partir do tema Lipólise e beta-oxidação, parte 2. 


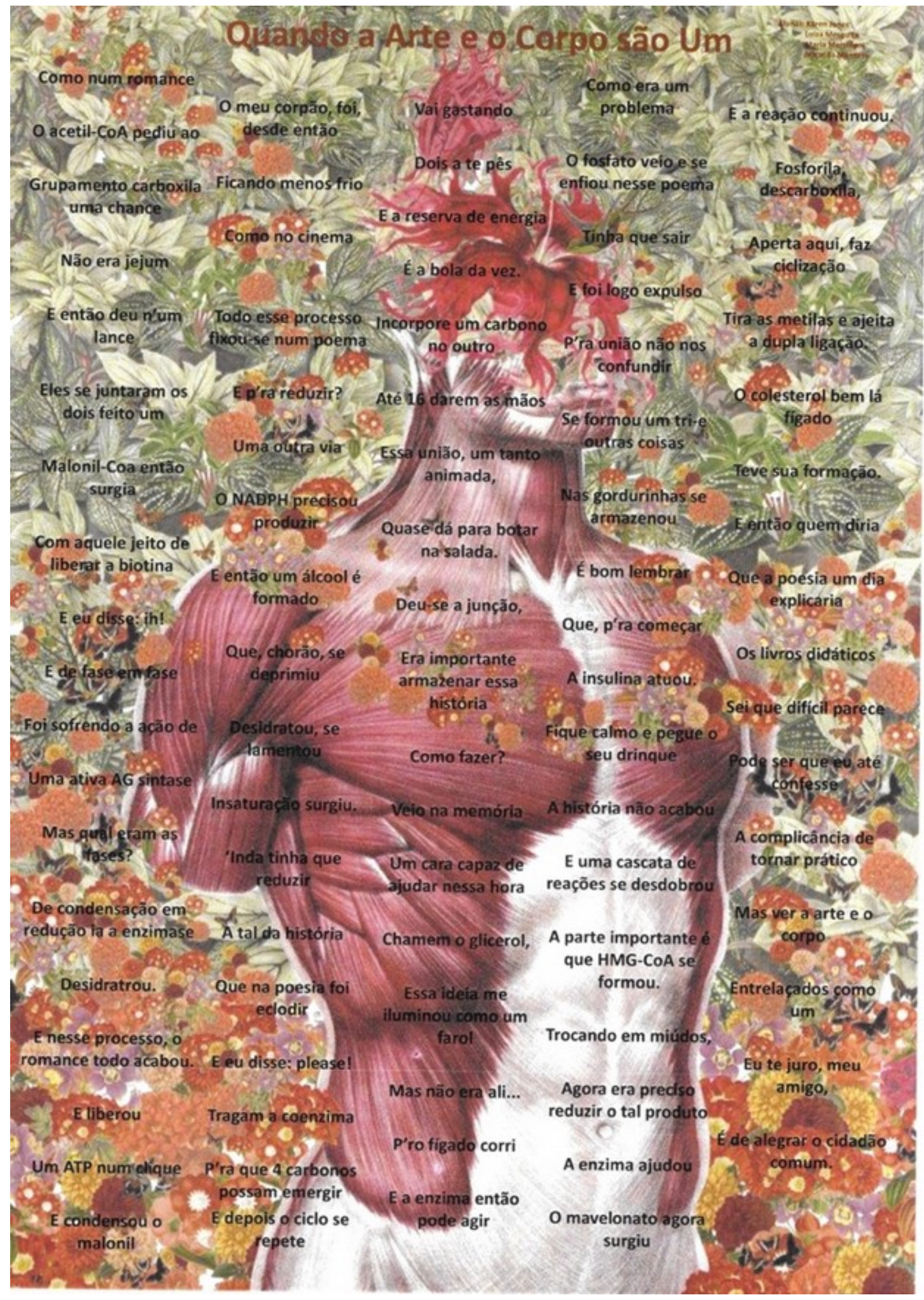

Poema elaborado a partir do tema Lipogênese. 


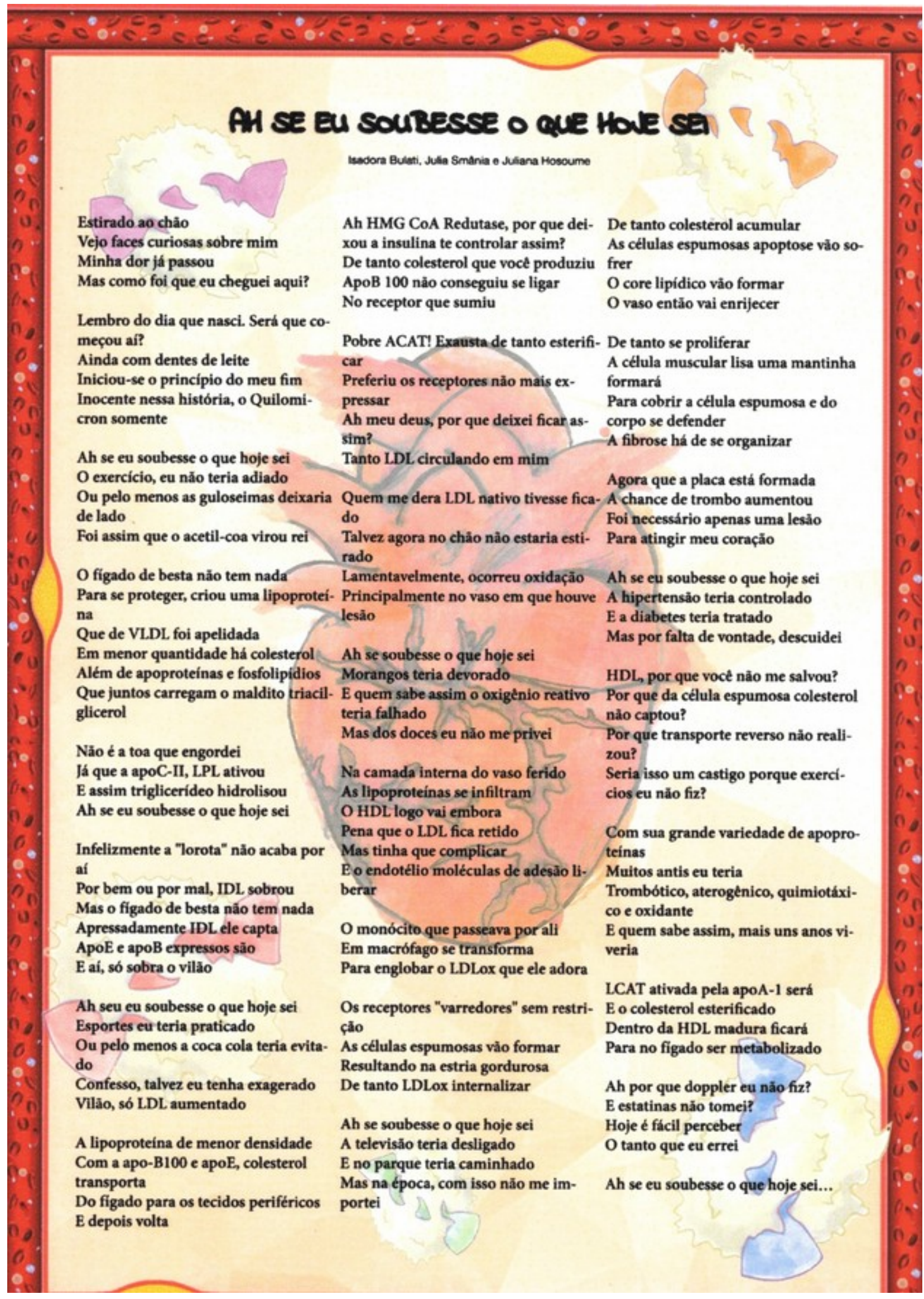

Poesia elaborada a partir do tema Metabolismo das lipoproteínas e Aterosclerose. 


\section{Poema elaborado a partir do tema Lipogênese.}

\section{ENERGIA DE CORPO E ALMA}

Um poema, disse ela, em um đia da semana, em uma manhã tăo bela. Será um đesafio, mas um đesafio aceito, pois sinto aqui no meu peito que com três autoras diferentes um poema pode ser feito. E um pedido đe compreensáo, pois pode nấ estar perfeito, mas fol feito com o coraçăo.

Sentada na minha mesa, estudando ao amanhecer, pensando cada vez o que poderia ser; aquilo que todos vivem, todos temem; pela qual todos correm para perder; Hpidios acumulados em locais indesejados, mas se com cuidado, bem manejados, um bem enorme podem fazer. Desde a cor dos seus olhos, a cofatores enzimáticos, mensageiros celulares lipidios estáo presentes; até hormônios, đeles são provenientes; e ainda ancoram proteinas đe membrana, sem esquecer đos detergentes.

Todavia, na ingesta de carboidratos e proteinas, não podemos nos exceder, pois a partir desses substratos, e da açăo da insulina, é que o nosso corpo ácido graxo val produzir, a tío temivel gordurinha, difieil de perder. Tudo se inieia, quando o ATP começa a acumular, e junto com ele o Acetil-CoA, que perde seu CoA e na uniľo com o oxaloacetato, citrato văo formar, ATP quando em grande quantidade a isocitratodesidrogenase inibirá; o citrato por sua vez, no ciclo đe Krebs não val entrar, đa mitocôndria ele terá que se retirar, seu transportador de membrana certamente irá the auxillar. No citosol, a enzima citratoliase irá catalisar, o eitrato em Acetil mais oxaloacetato se transformará, agora o CoA poderá de novo se juntar, mas esse CoA đaqui, náo é o mesmo CoA de lá, pois na membrana da mitocóndria, nenhum dos dois conseguem atravessar. Pronto o Acetil-CoA está formado novamente, como matéria-prima pode ser usado na lipogênese; mas e o oxaloacetato, qual será seu paradeiro? Será seu destino corriqueiro? Sim, à mitocōndria terh̆ de retornar, mas por onde? Pela membrana, ele năo consegue passau, em malato ou piruvato terá que se modificar. Na primeira opẹăo, energia irá gastax, a enzima málica nảo irá se conformar, e nessa hora ela entra pra orientar, em piruvato é mais viável se metamorfosear, um NADPH đaqui irá se procriar, e na biossintese ele será elementar.

Mas chega de conversa jogada fora, agora o papo é sério; biossintese de lipidios, desvendando esse mistério; A Acetil. Coa Carboxilase catalisa Acetil-CoA, e isso tudo é só pra começar; mas essa enzima, eu preciso te đizer, tem três partes componentes, é fácil compreender; A primeira parte b́ a biotina, proteina carreadora, a segunda é a biotina-carboxilase, tăo encantadora, e a outra pra completar é a transcarboxilase, difieil đe rimar. Mas continuando esse processo, voltando à catálise, malonil Coa será formado em uma sequêneia de fases. O bicarbonato se liga à biotina e se ancora na biotinacarboxilase, tornam-se ativado, năo 6 um processo demorado mas gasta energia; parece até magia, mas o acetil-Coa, sim ele mesmo que estava a alguns versos acima, agora entra em açío, recebendo um $c 02$ da tranferase, termina o malonil a sua formaçlio. Calma, respire, deixe o ar entrar, porque por mais complicado, sempre pode piorar; já abandonei a minha mesa, na minha cama estou deitada olhando para o seu nome, uma enzima renomada. Ácido graxo sintase, quase parece invençĭo; 7 sitios ativos em sua cadeia, cada um com uma funçăo. Sâo várias proteinas que văo catalisar, formando ácidos graxos a partir de acetil e MaloniCoA; essa enzima é táo carinhosa, oferece seus braços para uma ligaçióo caprichosa; é tudo covalente, em grupos tióls do complexo, seus intermediários váo se ligar pro processo poder continuar.

ACP trabalhadora, um dos braços da acetil, é uma proteina transportadora, de grupos acila ouvi falar, ouvi também que 6 pequena, mas consigo ver a cena, do tio éster ligado a ela, uma hidrolise singela, que quebra essa ligaçấo e energia libera; importante na primeira reaçáo que torna viável, termodinamicamente favorível a continuidade de sua missiło; 0 Complexo enzimático tem anexo doissitios desconexos, cada qual se liga um substrato, o Acetil-Coa e Malonil-Coa; 0 sitio ativo 16 relativo ao Acetil-Coa, pois ao sitio ativo 2, vẻm se ligar depois, o Malonil-CoA. Por meio de uma reaçăo de condensaçắo b́ feita a ligaçio do Acetil-CoA ao Malonill-CoA pela Cetoacil-Sintase. Nesta reaçlo há a consumaçl̃o de uma Cetona no sítio 2 com liberaçấo de 1 carbono na forma de CO2. Esse carbono é o mesmo outrora introduxido no Malonil-Coa, formado a partir do bicarbonato, pela querida enzima Acetil-Coa Carboxilase. O próximo passo é a obtençî́o do álcool a partir da reduçẩo da Cetona, pela Cetoredutase, fazendo utilidade de um NADPH, que será oxidado (NADP+). O álcool formado 6 reelaborado por melo de uma desidrase. A đesidrataçăo promove a instauraçăo đe uma insaturaçăo nos carbonos 2 e 3 com a liberaçấo đe uma água. Outro NADPH será utilizado no próximo passo, com a formaçăo de um ácido graxo, pela reduçáo da dupla ligaçío do composto do sitio $2 \mathrm{com}$ a enoilredutase. Em seguida a tioesterase transfere esse composto para o posto 1 , deixando livre o posto 2 para a chegada de um novo Malonil-CoA recomeçando um novo ciclo. Sete eielos de condensaçấo e reduçăo formarío o Palmitoil saturado com 16 Carbonos ligados.

Biossintese de lipidios chegaste ao teu fim. Mas năo ao fim do meu poema, pois a regulaçăo é rigorosa e guarda seu dilema. Estimulada ou inibida, Acetil-CoACarboxilase é o nosso ponto de partida. Todos nela querem mandar, mas na verdade quem manda é ela, que se deixa regular, como o vento e o barco à vela. Glucagon e epinefrina, trabalham com fosforilaçăo, inativam essa enzima, covalente é a modulaçío.

Sấ đois hormônios điferentes, mas com muita habilldade, Acetil-CoACarboxilase agora perde sua atividade. $O$ produto final da blossintese também vad regular, fazendo feedback negativo, o Palmitoil-CoA.

Soberano o citrato estimula, nada nele é genérico, desempenha um papel central, é um ativador alostérico đa Citratosintase avivada, sem temor algum, ao mesmo tempo que inibe a fosfofrutoquinase 1. Por fim, mas năo menos importante, uma velha amiga resolve aparecer, insulina minha querida o que tens a oferecer? Na Aceti-CoAcarboxilase indiretamente vad agir, citratoliase ativada ela val atingir; Acetil-coa no citoplasma logo vad acumular, fazendo esse processo ainda mais andar. Essa moça de personalidade tăo particular, insulina formidável ensinando a regular.

o tempo passa, a vida envelhece e o corpo já năo obedece, o coraçăo bate mais forte, será đe alegria, será đe amor? Năo é o que parece. Voltando ao principlo, a partir da Acetil-CoA, sim ela está đe volta para sintetizar. Dessa vez está em excesso no periodo pós prandial, na presença de insulina, tem muito potencial. Duas moléculas de acetil se condensam formando acetoacetil-CoA, logo mais outra acetil se junta a ela para um composto formar; HMQ-coa sofre açío da HMG-coa redutase, que sem se intimidar, passa para a próxima fase, ocorre criaçî́o do mavelonato, que se converte em isopentenil e đimetilalil pirofosfato; logo uma sequência de condensaçbes vai acontecer, e quem surge é o esqualeno, esse fllhote nấo b́ pequeno; e o fechamento do anel vai converter; mas é o esqualenolinear que vai sofrer a conversăo? Certamente, no núcleo esterólde condensado chega ao produto final đa reaçáo. Finalmente colesterol é formado, esse moço é famoso, possui alguns transportadores por ser muito preguiçoso. E um processo energeticamente custoso, portanto $\mathbf{b}$ vantajoso, regular pela quantidade de colesterol ingerida, para que apenas complemente aquela que ali já existia. A HMO-CoAredutase b́ nosso ponto limitante, regulada pelo glucagon e pela insulina, hormónios que mudam o processo a cada instante; glucagon inativa e insulina faz o inverso, desfosforilaçấo e fosforilaçî̀ em um momento adverso. ACAT ativada pelo colesterol em alta concentraçáo intracelular, faz a sintese do colesterol de armazenamento logo aumentar. Enth̆o cuidado com os alimentos, porque uma đieta indevida, pode causar problemas sérios e acabar com a tua vida.

Agora me đespeço, mas năo sintas saudade, conhecimento é poder e isso sim é liberdade, biossintese đe lipidios és uma obra prima, e concluo esse poema com a minha simples rima.

Grupo 10 - Lipogènese - Fernanda Freitas Oliveira, Diana Herchonvicz de Oliveira e Fernanda Beltramin. 